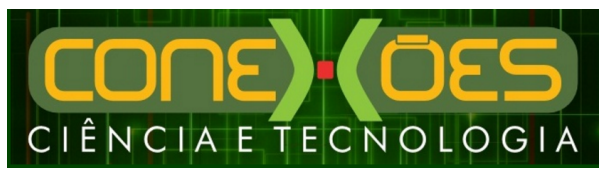

\title{
EDUCAÇÃO AMBIENTAL NOS LIVROS DIDÁTICOS ADOTADOS NO ENSINO FUNDAMENTAL PELO MUNICÍPIO DE ACARAÚ-CEARÁ
}

\author{
Maria José de Oliveira ${ }^{1}$, Eugênio Pacelli Nunes Brasil de Matos ${ }^{1}$ \\ ${ }^{1}$ Instituto Federal de Educação, Ciência e Tecnologia do Ceará (IFCE) \\ <mariaoliveirasilveira@gmail.com>,<eugeniopacelli.ifce@gmail.com>
}

DOI: 10.21439/conexoes.v12i3.1103

\begin{abstract}
Resumo. Discutir sobre os problemas ambientais torna-se cada vez mais pertinente, tendo em vista a crise ambiental que o planeta enfrenta. Uma maneira para favorecer discussões sobre o assunto é inserir essa temática no âmbito educativo. Dessa forma, reconhecem-se nesse trabalho os livros didáticos como uma possibilidade para inserção da educação ambiental no espaço escolar, uma vez que eles são uma das maiores ferramentas de apoio utilizadas pelos professores e alunos nas escolas. Portanto, o presente trabalho teve como objetivo, analisar os conteúdos relacionados à educação ambiental presentes nos livros didáticos adotados pelo município de Acaraú-Ceará em diferentes disciplinas no ensino fundamental. A metodologia foi baseada na técnica de análise de conteúdo, onde realizou-se a leitura de vinte e dois livros didáticos utilizados de primeiro ao quinto ano em cinco disciplinas do ensino fundamental e posteriormente os dados encontrados foram agrupados em categorias temáticas. Verificou-se que existe uma distribuição bastante desigual do tema transversal de meio ambiente nas diferentes disciplinas. Ciências foi a disciplina que mais apresentou trechos com referência a natureza e ambiente seguida por geografia e a disciplina que menos fez referência a aspectos ambientais foi história. Apesar da abordagem em todas as disciplinas o que se observou foi que na maioria das vezes não há uma intencionalidade de promover a reflexão indivíduo x ambiente, ou seja, ocorrendo de maneira desvinculada da realidade do aluno, sem contextualização e sem haver uma abordagem crítica acerca das questões ambientais.
\end{abstract}

Palavras-chaves: Ambiente escolar. Temática ambiental. Tema transversal.

\section{ENVIRONMENTAL EDUCATION IN TEXTBOOKS ADOPTED IN BASIC EDUCATION OF MUNICIPALITY ACARAÚ-CEARÁ}

\begin{abstract}
Discussing environmental problems is becoming increasingly relevant in view of the environmental crisis facing the planet. One way to favor discussions on this subject is to insert this theme in the educational field. Thus, textbooks are recognized as a possibility for insertion of environmental education into the school space, since they are one of the greatest support tools used by teachers and students in schools. Therefore, this study aimed to analyze the contents related to environmental education approached textbooks used by the municipality of Acaraú-Ceará in different disciplines in elementary education. The methodology was based on the technique of content analysis, where twenty-two textbooks were used from first, to fifth year in five subjects of elementary school and the data found were grouped in thematic categories. It was verified that there is a fairly unequal distribution of the transversal theme of the environment in the different disciplines. Sciences was the discipline that most presented excerpts with reference to nature and environment followed by Geography and the discipline that made less reference to environmental aspects was History. Despite the approach in all disciplines what was observed was that most of the times there is an intentionality to promote individual reflection versus environment, that is, occurring in a way unrelated to the reality of the student, without contextualization and without a critical approach about environmental issues.
\end{abstract}

Keywords: School environment. Environmental thematic. Cross-curricular theme.

Conex. Ci. e Tecnol. Fortaleza/CE, v.12, n. 3, p. 52 - 61, dez. 2018 


\section{INTRODUÇÃO}

A humanidade, desde sempre, apresentou, em sua existência, uma intima relação de dependência da natureza. Contudo, com o passar dos anos, observa-se que essa relação está se tornando cada vez menos sustentável. Malthus (1798) previu que o crescimento da população, em determinado momento, excederia a produção de alimentos que está diretamente relacionada à exploração de recursos naturais. Essa exploração desenfreada é apenas um de muitos outros fatores relacionados à crise ambiental atual (LEANDRO et al., 2015). Assim, é imprescindível que ocorra uma mudança no modelo de vida atual relacionado às questões ambientais, pois chegará ao ponto em que todo o planeta entrará em conflito, uma vez que ele já não conseguirá reestabelecer os recursos naturais com a mesma velocidade com que são consumidos (BIANCHINI et al., 2015).

Diante disso, é importante que a temática ambiental seja difundida para todas as pessoas, pois segundo Carvalho (2008), grande parte dos problemas ambientais está diretamente relacionada a condutas humanas inadequadas, geradas pelo desconhecimento global das consequências sobre o uso inadequado dos recursos. Dias (2010) cita que a Conferência de Estocolmo "nomeia o desenvolvimento da Educação Ambiental como um dos elementos mais críticos para que se possa combater rapidamente a crise ambiental do mundo". Sendo assim a educação é um dos principais e mais eficazes caminhos para que ocorra a discussão e incorporação da consciência ambiental, ou seja, é um dos mais importantes meios para que isto seja alcançado (MORAES 2009). A escola, enquanto instituição de ensino, tem grande responsabilidade na formação e inserção social do educando. Portanto, uma atenção especial deve ser dada aos conflitos ambientais que fazem parte do cotidiano da humanidade afetando a todos, direta ou indiretamente (XAVIER et al., 2011).

Dessa maneira, considera-se, neste trabalho, os livros didáticos como uma das principais ferramentas para a efetivação desse repasse de conhecimento, já que os mesmos prevalecem nas salas de aula como principal instrumento de trabalho e fonte de pesquisa do professor, embasando e direcionando significativamente o trabalho docente (DELIZOICOV; ANGOTTI; M., 2011). Reconhece-se que os livros didáticos são um veículo de extrema importância na educação dos alunos.

Nessa perspectiva, considera-se pertinente a realização desse trabalho, que tem o objetivo de analisar os conteúdos de educação ambiental presente nos livros didáticos adotados no ensino fundamental pelo município de Acaraú-Ceará, visando compreender quais os assuntos mais abordados sobre educação ambiental nos livros didáticos, dado que esse é um recurso que se estabelece como uma das principais formas de documentação e de consulta utilizadas nas escolas públicas (BRASIL, 2004).

\section{FUNDAMENTAÇÃO}

\section{Segundo Brasil (1999)}

"Entendem-se por educação ambiental os processos por meio dos quais o indivíduo e a coletividade constroem valores sociais, conhecimentos, habilidades, atitudes e competências voltadas para a conservação do meio ambiente, bem de uso comum do povo, essencial à sadia qualidade de vida e sua sustentabilidade."

Este conceito começou a tomar forma em meados da década de 60 e consolidou-se na década de 70, quando a preocupação com o ambiente começou a tomar cada vez mais espaço nos debates mundiais a respeito da relação homem x ambiente (DIAS, 2010). Conteúdos desta natureza devem estar presentes na rotina da sala de aula, sendo trabalhados de forma transversal e podendo ser abordados por meio de várias estratégias no ambiente escolar (BRASIL, 1997b). A transversalidade encontra apoio legal nos Parâmetros Curriculares Nacionais (PCNs), estabelecidos com a finalidade de construir uma referência curricular comum para o país (BRASIL, 1997b).

Desse modo, cada vez mais a educação ambiental vem sendo incorporada ao currículo escolar, sendo hoje tão pertinente que se tornou obrigatória por força de lei específica (BRASIL, 1999). A Lei n ${ }^{\circ}$ 9.795, de 27 de abril de 1999, também foi criada com o intuito de fortalecer a presença da educação ambiental no ambiente escolar. Ela estabelece, no artigo 10, que "A educação ambiental será desenvolvida como uma prática educativa, integrada, contínua e permanente em todos os níveis e modalidades do ensino formal" (BRASIL, 1999). Para Cuba (2010), a educação ambiental começou a ser reconhecida com maior ênfase depois da promulgação da referida lei.

Dessa forma, esses dois principais documentos enfatizam que a educação ambiental deve ser abordada de forma obrigatória no âmbito educativo, de maneira transversal. Portanto, como perspectiva educativa, esse tema deve estar presente no currículo de todas as disciplinas, uma vez que permite a análise de conteúdos que enfocam as relações entre a humanidade, o meio natural e as relações sociais, sem esquecer-se das particularidades de cada disciplina (VIEIRA, 2008).

Esclarecida a importância de se discutir sobre meio ambiente no espaço escolar, é preciso agora viabilizar 
maneiras para se inserir essa temática na escola. Os livros didáticos são o caminho para que isso ocorra. Eles representam uma das principais ferramentas de trabalho, em forma de documento impresso, utilizados na sala de aula, tornando-se um recurso importante para o aluno e para o professor, no processo de ensinoaprendizagem. O mesmo tem sido utilizado de diferentes formas pelos professores no ensino fundamental, (FRISON; VIANNA J.; CHAVES; BERNARDI, 2009).

Segundo Freitas e Rodrigues (2008), o livro didático tem uma grande importância na formação do aluno, principalmente pelo fato de, muitas vezes, ser o único com o qual o aluno entra em contato, não havendo muita interação dos mesmos com outros materiais e informações de outras fontes. Desta forma, eles se constituem como uma ótima ferramenta de ensino. Mas é importante considerar que esse não deve ser o único material a ser utilizado, pois os estudantes devem ter acesso a uma variedade de fontes de informação. Esse material sendo ou não intensamente usado pelos alunos é, provavelmente, a principal referência da grande maioria dos educadores. No entanto, considera-se que os mesmos não podem ser reféns dessa única fonte, por melhor que seja a sua qualidade (DELIZOICOV; ANGOTTI; M. 2011).

\section{METODOLOGIA}

O presente trabalho foi realizado no município de Acaraú, que se localiza no litoral oeste do estado do Ceará. Possui um território de $842,559 \mathrm{~km}^{2}$, a população estimada é de 62.199 pessoas em 2018. Com relação à educação básica, o município dispõe de 1 Instituto Federal, 9 escolas estaduais, 42 escolas municipais e 6 escolas privadas; possui um Índice de Desenvolvimento da Educação Básica (IDEB) de 4,5 para os anos finais do ensino fundamental (IBGE, 2018).

Nesse estudo foi realizada a análise dos conteúdos relacionados ao ambiente, presentes nos livros didáticos adotados pelo município de Acaraú-Ceará. A análise dos livros foi baseada na técnica de análise de conteúdo descrita por (BARDIN, 1977), que a caracteriza, enquanto método, como um conjunto de técnicas de análise das comunicações que utilizam metodologias sistemáticas e objetivas de descrição do conteúdo de mensagens, permitindo inferências de conhecimentos relativos às condições de produção destas mensagens.

A realização da análise de conteúdo foi realizada em três fases: (i) a pré- análise; (ii) a exploração do material; e (iii) o tratamento dos resultados - a inferência e a interpretação ((BARDIN, 1977).

A fase de pré-análise foi a primeira fase da pesquisa, onde ocorreu a escolha dos documentos a serem sub- metidos à análise e também a formulação de hipóteses e objetivos para a elaboração de indicadores para a interpretação final (BARDIN, 1977). Sendo assim, após terem sido elaboradas as hipóteses e os objetivos deste trabalho, foi realizada a escolha dos livros didáticos utilizados em cinco diferentes disciplinas do ensino fundamental do primeiro ao quinto ano: língua portuguesa, matemática, ciências, geografia e história. Foram analisadas sete coleções diferentes. O critério para selecionar as coleções foi o fato de serem utilizadas pela rede pública do município de Acaraú. As coleções, títulos dos livros, disciplinas, autores e os anos onde são utilizadas, são especificados com as letras de A a G (ver Tabela 1).

Da coleção A foram analisados três livros de língua portuguesa, que são utilizados do primeiro ao terceiro ano; já na coleção B foram analisados dois livros da mesma disciplina, utilizados no quarto e quinto ano. Na coleção $\mathrm{C}$, foram analisados três livros de matemática, adotados do primeiro ao terceiro anos e da coleção D analisou-se dois livros da mesma disciplina. Na coleção $\mathrm{E}$ foram analisados quatro livros de história, utilizados do segundo ao quinto ano. A mesma quantidade de livros foi analisada nas coleções $F$ e $G$, utilizadas do segundo ao quinto ano, nas disciplinas de ciências e geografia respectivamente.

Ao todo foram analisados vinte e dois livros, sendo que o primeiro ano não utiliza livros didáticos em três disciplinas: ciências, história e geografia.

Na segunda fase da técnica de Bardin (1977), fase da exploração do material, foram aplicadas as técnicas e as formas de análise de acordo com os objetivos pretendidos. Nesse momento foi realizada a observação e a leitura minuciosa, página a página, de todos os livros didáticos, fazendo a anotação de cada trecho de conteúdo que faz referência a algo relacionado à natureza e ao ambiente, tomando nota da página ou número de páginas.

$\mathrm{Na}$ terceira fase, tratamento dos resultados, ocorreu a inferência e a interpretação dos dados que haviam sido anotados durante a segunda fase. Nesta etapa, Bardin (1977) ressalta que os dados podem ser agrupados em categorias temáticas conforme o que foi encontrado, sendo assim o autor livre para fazer estes agrupamentos conforme objetivo do estudo.

Para melhor organização dos dados, os livros foram analisados por disciplina. Para cada uma, foi elaborada uma tabela indicando os livros referentes à disciplina, o ano que está sendo analisado, colocando os temas encontrados nos livros didáticos e especificando a presença dos mesmos através da identificação do número de páginas presente em cada livro que possui uma abor- 


\begin{tabular}{|c|c|c|}
\hline COLEÇÃO & TÍTULO / REFERÊNCIA & ANO \\
\hline \multicolumn{3}{|c|}{ Livros de língua portuguesa } \\
\hline A & $\begin{array}{l}\text { Rumo a novos letramentos: letramento e alfabetização: língua Portuguesa. } \\
\text { (CHANOSQUI-GUSSO; FINAU, 2011) }\end{array}$ & $1^{\circ}$ ano \\
\hline A & $\begin{array}{l}\text { Rumo a novos letramentos: letramento e alfabetização: língua Portuguesa. } \\
\qquad \text { (CHANOSQUI-GUSSO; FINAU, 2011) }\end{array}$ & $2^{\circ}$ ano \\
\hline A & $\begin{array}{l}\text { Rumo a novos letramentos: letramento e alfabetização: línguaPortuguesa. } \\
\text { (CHANOSQUI-GUSSO; FINAU, 2011) }\end{array}$ & $3^{\circ}$ ano \\
\hline B & Ápis: língua portuguesa. (BORGATTO; BERTIN; MARCHEZI 2011) & $4^{\circ}$ ano \\
\hline B & Ápis: língua portuguesa. & $5^{\circ}$ ano \\
\hline \multicolumn{3}{|c|}{ Livros de matemática } \\
\hline $\mathrm{C}$ & Agora é hora: alfabetização matemática (PRADO 2011) & $1^{\circ}$ ano \\
\hline $\mathrm{C}$ & Agora é hora: alfabetização matemática (PRADO 2011) & $2^{\circ}$ ano \\
\hline $\mathrm{C}$ & Agora é hora: alfabetização matemática (PRADO 2011$)$ & $3^{\circ}$ ano \\
\hline $\mathrm{D}$ & Fazendo e compreendendo: matemática (SANCHEZ; LIBERMAN 2011) & $4^{\circ}$ ano \\
\hline $\mathrm{D}$ & Fazendo e compreendendo: matemática $(\overline{\text { SANCHEZ; LIBERMAN }} \mid 2011)$ & $5^{\circ}$ ano \\
\hline \multicolumn{3}{|c|}{ Livros de história } \\
\hline $\mathrm{E}$ & Porta Aberta: história (LIMA 2011) & $2^{\circ}$ ano \\
\hline $\mathrm{E}$ & 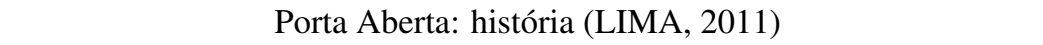 & $3^{\circ}$ ano \\
\hline $\mathrm{E}$ & Porta Aberta: história ( $\overline{\text { LIMA 2011) }}$ & $4^{\circ}$ ano \\
\hline $\mathrm{E}$ & Porta Aberta: história (LIMA 2011) & $5^{\circ}$ ano \\
\hline \multicolumn{3}{|c|}{ Livros de ciências } \\
\hline $\mathrm{F}$ & Projeto Buriti: ciências (BEZERRA 2011) & $2^{\circ}$ ano \\
\hline $\mathrm{F}$ & Projeto Buriti: ciências (BEZERRA, 2011) & $3^{\circ}$ ano \\
\hline $\mathrm{F}$ & Projeto Buriti: ciências (BEZERRA, 2011) & $4^{\circ}$ ano \\
\hline $\mathrm{F}$ & Projeto Buriti: ciências (BEZERRA & $5^{\circ}$ ano \\
\hline \multicolumn{3}{|c|}{ Livros de geografia } \\
\hline $\mathrm{G}$ & Projeto Buriti: geografia (MAESTU, 2011) & $2^{\circ}$ ano \\
\hline G & Projeto Buriti: geografia (MAESTU, 2011) & $3^{\circ}$ ano \\
\hline G & Projeto Buriti: geografia (MAESTU, 2011) & $4^{\circ}$ ano \\
\hline \multirow[t]{2}{*}{ G } & Projeto Buriti: geografia (MAESTU, 2011) & $5^{\circ}$ ano \\
\hline & QUANTIDADE TOTAL DE LIVROS ANALISADOS & 22 \\
\hline
\end{tabular}

Fonte: Elaborada pela autora.

dagem ambiental. Foi mencionado também o número total de páginas presentes em cada livro. Foi verificada a porcentagem de páginas, em cada livro, por disciplina, que apresentam conteúdos sobre o ambiente.

Embora a análise de conteúdo deixe o pesquisador livre, pode-se dizer que a métrica utilizada neste trabalho foi a presença ou ausência nas páginas dos livros onde se encontravam conteúdos que faziam alguma referência ao ambiente natural, aos seus cuidados ou à sua alteração. Não se utilizou uma métrica mais detalhada de volume textual como frase, parágrafo ou meia página por se entender que a simples presença ou ausência do assunto pode servir de ponto de partida para o desenvolvimento do tema pelo docente, além de estar mais adequada ao objetivo do trabalho.

\section{RESULTADOS E DISCUSSÃO}

$\mathrm{Na}$ análise dos livros didáticos de Língua portuguesa notou-se que há a presença de temas relacionados ao ambiente; no entanto, muitas vezes ocorre de forma sucinta e não intencional de incitação ao debate das questões ambientais. Por não ser o foco da disciplina, aparece principalmente na forma de textos ou frasesexemplos de aplicação da língua portuguesa (Tabela 2).

Verificou-se que os trechos relacionados a animais são os mais frequentes, sendo agrupados na categoria temática intitulada "textos sobre animais". Do primeiro ao quinto ano, todos os livros abordaram algum texto sobre o assunto, mesmo que citados rapidamente e sem o intuito de desenvolver a ideia de cuidados com o ambiente. $\mathrm{O}$ conteúdo está distribuído em uma diversidade 
Tabela 2: Análise dos livros didáticos de língua portuguesa.

\begin{tabular}{|c|c|c|c|c|c|}
\hline LIVROS DE LÍNGUA PORTUGUESA & $\begin{array}{c}\mathbf{1}^{\mathbf{o}} \\
\text { ano }\end{array}$ & $\begin{array}{c}2^{\mathbf{0}} \\
\text { ano }\end{array}$ & $\begin{array}{c}3^{\circ} \\
\text { ano }\end{array}$ & $\begin{array}{c}4^{\circ} \\
\text { ano }\end{array}$ & $\begin{array}{c}5^{\circ} \\
\text { ano }\end{array}$ \\
\hline Total de páginas do livro & 303 & 237 & 199 & 216 & 264 \\
\hline TEMÁTICAS & \multicolumn{5}{|c|}{$\begin{array}{c}\mathrm{N}^{o} \text { de páginas que fazem referência ao } \\
\text { meio ambiente }\end{array}$} \\
\hline Informações sobre plantas ou áreas verdes & 1 & 10 & - & 2 & - \\
\hline Poluição do meio ambiente & 2 & - & - & - & - \\
\hline Atitudes que contribuem para um ambiente sustentável & - & - & 1 & - & - \\
\hline Textos sobre animais & 11 & 6 & 13 & 12 & 10 \\
\hline Total de pag. que fazem referência ao meio ambiente & 14 & 16 & 14 & 14 & 10 \\
\hline Porcentagem de pag. que fazem referência ao meio ambiente & $4,60 \%$ & $6,70 \%$ & $7,00 \%$ & $6,50 \%$ & $3,80 \%$ \\
\hline
\end{tabular}

Fonte: Elaborada pela autora.

de gêneros textuais, principalmente fábulas, músicas, poemas e textos informativos. Porém, notou-se que não enfocam a questão ambiental em si.

Segundo Ferreira (2013), o trabalho com os gêneros textuais favorece o processo de ensino-aprendizagem, pois os aspectos linguísticos e discursivos poderão ser explorados de forma contextualizada e as discussões poderão proporcionar um trabalho, não somente com os conteúdos dos textos, mas também com as suas formas de organização e com as suas funções sociais, levando o aluno a pensar de forma crítica sobre o ambiente.

É importante ressaltar que temas como os citados, principalmente sobre plantas e animais são vistos frequentemente nos livros didáticos, inseridos nos textos, já que são assuntos presentes no cotidiano das pessoas. O que falta é uma contextualização dos temas, pois o professor torna a aprendizagem significativa para o aluno quando contextualiza as suas aulas. Assim, além de proporcionar uma aprendizagem eficaz para ele, as aulas contextualizadas estimulam a valorização do ambiente próximo ao educando, como a fauna e flora, por exemplo, presentes em sua região (SALES; LANDIN. 2009). Dessa maneira, os livros didáticos de língua portuguesa não trazem uma interpretação e compreensão dos textos focadas no debate ambiental, fazendo com que o aluno não pense de forma crítica sobre o ambiente.

Ao fazer um comparativo quanto à porcentagem de páginas em que os livros apresentam com enfoque ambiental, relacionado ao número de páginas total que cada livro contém, notou-se que o livro do terceiro ano é aquele onde há uma maior presença de temas relacionados ao ambiente: $7 \%$. Comparado com os livros dos outros anos, o do quinto ano é o que menos destaca assuntos sobre o ambiente, apenas 3,8\%. Ainda assim, considera-se que todos os livros abordam muito pouco sobre esse tema.
Através desses dados, observa-se que os livros didáticos de língua portuguesa precisam explorar de forma mais efetiva as questões ambientais e que ainda há uma carência da abordagem desses conteúdos nos mesmos.

Nos livros didáticos de Matemática, também há pouca predominância de assuntos sobre o ambiente (ver Tabela 3). Quase todos os temas foram encontrados nos livros em forma de situações-problema envolvendo o assunto. Estes trabalham muito com exercícios de fixação e situações-problema que em sua maioria apenas exigem que o aluno memorize uma situação ou simplesmente aplique a parte numérica nos exercícios. Ocorrendo isso de forma meramente mecânica, sem trazer discussões mais vinculadas às questões ambientais.

O conteúdo relacionado às "situações-problema envolvendo animais" são abordados nos livros do primeiro ao quarto ano, enquanto que no livro do quinto ano não foi verificada a presença do tema. Observou-se que o que se relaciona ao ambiente tem apenas o objetivo de apresentar alguma informação numérica.

Essa análise é comparada com o trabalho de Marpica e Logarezzi (2008), que também verificaram livros de matemática e constataram que a proposta de ensino e aprendizagem da matemática, explícitas nos mesmos, não abrangem contextualizações e discussões mais detalhadas dos temas transversais. A maioria dos exemplos e exercícios de fixação são fictícios e descontextualizados, sendo perdidas as chances de vincular os assuntos às questões ambientais. Notou-se que a temática ambiental apesar de estar presente nos livros didáticos escolhidos, não traz maiores discussões sobre esse assunto, nem deixa um ponto de partida para se trabalhar esse tema, como pode correr nos livros de português.

Pode ser observado que o livro de matemática que possui maior enfoque ambiental é o livro utilizado no primeiro ano, contendo $11 \%$ das páginas sobre essa temática. Já no livro do quinto ano é onde menos se dis- 


\begin{tabular}{|c|c|c|c|c|c|}
\hline LIVROS DE MATEMÁTICA & $\begin{array}{c}\mathbf{1}^{\mathbf{0}} \\
\text { ano }\end{array}$ & $\begin{array}{c}2^{\mathbf{o}} \\
\text { ano }\end{array}$ & $\begin{array}{c}3^{\mathbf{0}} \\
\text { ano }\end{array}$ & $\begin{array}{c}4^{\circ} \\
\text { ano }\end{array}$ & $\begin{array}{c}5^{\circ} \\
\text { ano }\end{array}$ \\
\hline Total de páginas do livro & 175 & 223 & 271 & 240 & 256 \\
\hline TEMÁTICAS & \multicolumn{5}{|c|}{$\begin{array}{l}\mathrm{N}^{\mathrm{o}} \text { de páginas que fazem referência ao } \\
\text { meio ambiente }\end{array}$} \\
\hline Situações-problema sobre poluição, lixo ou reciclagem & 1 & - & 1 & - & 1 \\
\hline Situações-problema envolvendo animais & 15 & 9 & 5 & 7 & - \\
\hline Situações-problema envolvendo plantas & 3 & 5 & 1 & 3 & 1 \\
\hline $\begin{array}{l}\text { Situações-problema envolvendo a preservação } \\
\text { dos recursos hídricos }\end{array}$ & - & - & & 1 & - \\
\hline Total de pag. que fazem referência ao meio ambiente & 19 & 14 & 7 & 10 & 2 \\
\hline Porcentagem de pag. que fazem referência ao meio ambiente & $11,00 \%$ & $6,30 \%$ & $2,60 \%$ & $4,00 \%$ & $0,80 \%$ \\
\hline
\end{tabular}

cute o assunto. Ele possui $0,8 \%$ de assuntos contendo temas ambientais. Destaca-se que esse quantitativo de abordagem se restringe a muito pouco, não favorecendo uma construção significativa de opiniões críticas que contribuam para melhorias no ambiente.

Diante disso, é possível perceber a presença de falhas na composição e organização do tema transversal. Esses conteúdos são raramente propostos, e quando aparecem subutiliza-se seu potencial exploratório. Sendo assim, os livros de matemática estão longe de favorecer uma compreensão mais complexa sobre as questões que se referem ao ambiente.

Nos livros de geografia (Tabela 4), percebeu-se que eles, em sua totalidade, até abrangem os assuntos sobre o ambiente mais efetivamente, mas deve-se destacar que alguns temas são colocados sem contexto. Isso é observado na forma de apresentação do conteúdo, nas atividades propostas, no desenvolvimento dos conceitos, e no decorrer das páginas. Muitas vezes esses temas são abordados de forma inadequada à realidade local ou às práticas sociais do educando. Por esse motivo, ressalta-se a importância de utilizar, não apenas o livro didático, como também diferentes recursos pedagógicos, que ofereçam ao aluno uma vasta fonte de informações (MELO; GROENWALDO, 2012).

Para Oliveira (2008), o ensino-aprendizagem nessa área pode ser caracterizado pela veiculação aparente dos discursos midiáticos e aplicação de conteúdos de forma desvinculada dos contextos locais. Dessa forma, reconheceu-se que a utilização do livro didático na disciplina de Geografia é indispensável, porém, é necessário se ter muito cuidado para que ele não seja usado como a única ferramenta metodológica em sala de aula. É importante que o conhecimento seja disseminado de diferentes formas, sem restringir-se apenas as informações dos livros didáticos.
Quanto à quantidade de páginas total de cada livro e a quantidade de páginas que são destinadas à abordagem ambiental, verificou-se que o livro do quarto ano é onde se encontra um maior enfoque ambiental. Nele, $26 \%$ das páginas contém assuntos ambientais. Onde menos se discute o assunto é no livro do quinto ano, $11 \%$. Ainda assim, reconhece-se que os temas sobre educação ambiental são colocados em foco em muitas situações, possuindo uma grande abrangência de temas sobre esse assunto.

Ao realizar a análise dos livros didáticos de ciências (Tabela 5), constatou-se que a presença de trechos que fazem referência a aspectos da natureza ou do ambiente aparecem de forma não objetiva, não incitando a reflexão do aluno sobre questões ambientais. A maioria tem a função apenas de informar sobre aspectos ambientais, sem contribuir para um pensamento crítico do aluno acerca das questões ambientais. Por se tratar de livros de ciências, esperava-se que os assuntos estivessem em sua maioria voltados para as questões ambientais. Porém o que se percebeu foi que alguns conteúdos até possuem uma abordagem ambiental, mas estão descritos sem muita abrangência ambiental e de forma fragmentada.

Compara-se essa análise com o trabalho realizado por Moraes (2009), onde o mesmo constata a presença de conteúdos relacionados ao ambiente na coleção Projeto Pitanguá e ressalta que as questões relacionadas ao meio ambiente aparecem de formas isoladas do restante do texto. Na maioria das vezes, o seu conteúdo se restringe à descrição de características da vida de plantas e animais, que é o que acontece com os assuntos sobre o ambiente observados no livro didático de ciências investigado nesse trabalho.

Para Martins e Guimarães (2002) os livros didáticos em grande maioria confundem o papel da educação 


\begin{tabular}{|c|c|c|c|c|}
\hline LIVROS DE GEOGRAFIA & $2^{\circ}$ ano & $3^{\circ}$ ano & $4^{0}$ ano & $5^{0}$ ano \\
\hline Total de páginas do livro & 112 & 136 & 145 & 152 \\
\hline TEMÁTICAS & \multicolumn{4}{|c|}{$\begin{array}{l}\mathrm{N}^{\mathrm{o}} \text { de páginas que fazem referência ao } \\
\text { meio ambiente }\end{array}$} \\
\hline $\begin{array}{l}\text { Cuidados e transformações ocorridas com as diferentes } \\
\text { paisagens naturais }\end{array}$ & 1 & 8 & 5 & 6 \\
\hline Boas práticas de agricultura & 1 & 2 & - & - \\
\hline Poluição, transformação ou destruição do meio ambiente & 4 & - & 1 & - \\
\hline Reciclagem e coleta seletiva & 4 & 2 & - & - \\
\hline Preservação de recursos hídricos & 3 & 11 & 2 & - \\
\hline $\begin{array}{l}\text { Atitudes antrópicas que atrapalham o meio ambiente } \\
\text { (desmatamento, extrativismo, poluição dos rios, queimadas) }\end{array}$ & - & 3 & 6 & 5 \\
\hline Extinção de animais & - & - & - & 1 \\
\hline $\begin{array}{l}\text { Textos informativos sobre meio ambiente } \\
\text { (conferências, encontros ambientais) }\end{array}$ & - & - & - & 1 \\
\hline Atitudes que contribuem para um meio ambiente sustentável & - & 1 & 4 & 2 \\
\hline Efeito estufa e aquecimento global & - & - & 6 & - \\
\hline Biomas brasileiros & - & - & 4 & 2 \\
\hline Total de pag. que fazem referência ao meio ambiente & 13 & 27 & 38 & 17 \\
\hline Porcentagem de pag. que fazem referência ao meio an & $12,00 \%$ & $20,00 \%$ & $26,00 \%$ & $11,00 \%$ \\
\hline
\end{tabular}

Fonte: Elaborada pela autora.

ambiental. Eles limitam-se a oferecer informações sobre meio ambiente, voltadas para temas como ecologia, fauna, flora e biodiversidade, desmatamento e lixo. Tais assuntos são de importante abordagem, entretanto, sem a consideração e a ênfase relacionadas aos valores humanos, falta-lhes sentido. Dessa forma, não é atingida a consistência requerida para que haja as mudanças desejadas acerca da sensibilização, a percepção do meio ambiente e a transformação de postura diante das questões ambientais.

Acredita-se que esse tema transversal precisa estar mais presente nos livros didáticos de ciências. Nos livros do segundo e quarto ano, há $23 \%$ e $24 \%$ de páginas abordando aspectos ambientais respectivamente. Não se esperava esse resultado por se tratar de uma disciplina que deveria abordar especificamente temas ambientais, estimulando o aluno a pensar sobre a natureza que o cerca, não com informações soltas, mas articulada com os conteúdos e conceitos que estiveram sendo estudados.

Apesar da porcentagem média de presença de temas ambientais em livros de ciências ser de $21 \%$ para todas as séries avaliadas, está ainda é a disciplina que mais investe em meio ambiente justamente pela sua essência discriminada nos parâmetros curriculares nacionais $1^{\mathrm{a}}$ à $4^{\mathrm{a}}$ Série (BRASIL, 1997a) em seu volume 04 Ciências da Natureza, que destaca que "os problemas relativos ao meio ambiente e à saúde começaram a ter presença quase obrigatória em todos currículos de Ciências Naturais, mesmo que abordados em diferentes níveis de profundidade e pertinência".

Nos livros de história, os temas sobre o ambiente são escassos e as questões ambientais são pouco frequentes (ver Tabela 6).

Os PCNs (BRASIL, 1998), ao discutirem sobre o ensino de história, destacam que todos os alunos devem perceber-se integrantes, dependentes e agentes transformadores do ambiente, sendo capazes de identificar seus elementos e as interações entre eles, contribuindo ativamente para a melhoria do meio ambiente. Mas, para que haja essa interação entre aluno e ambiente, faz-se necessário que esse conteúdo seja inserido no currículo escolar de forma transversal, de maneira efetiva e contextualizada.

No trabalho de Abílio et al. (2004), salienta-se que os temas relacionados ao ambiente, na maioria das vezes, refletem poucos aspectos de uma educação ambiental crítica, privilegiando o domínio de conceitos científicos sem abranger a totalidade dos processos que levam à degradação ambiental e à redução da qualidade de vida dos seres humanos e demais seres vivos. Abordagens realizadas dessa maneira pouco contribuem para a formação de sujeitos críticos, participativos e capazes de uma transformação de atitude em relação às questões ambientais.

Para Carvalho (2008), os profissionais da área de 
Tabela 5: Análise dos livros didáticos de Ciências.

\begin{tabular}{ccccc}
\hline LIVROS DE CIENCIAS & $\mathbf{2}^{\mathbf{0}}$ ano & $\mathbf{3}^{\mathbf{0}}$ ano & $\mathbf{4}^{\mathbf{0}}$ ano & $\mathbf{5}^{\circ}$ Ano \\
\hline Total de páginas do livro & 144 & 159 & 168 & 168 \\
TEMÁTICAS & $\mathrm{N}^{\circ}$ de páginas que fazem referência ao \\
& \multicolumn{4}{c}{ meio ambiente }
\end{tabular}

As diferentes paisagens naturais

Atitudes antrópicas que atrapalham o meio ambiente

Preservação de plantas ou áreas verdes

Os animais e sua preservação

$\begin{array}{llll}4 & 2 & 4 & 5 \\ 3 & 2 & - & 4\end{array}$

Cuidados com o solo

Preservação de recursos hídricos

Cuidados com o lixo, reciclagem ou coleta seletiva

Biomas brasileiros

Preservação dos recursos naturais

Efeito estufa e aquecimento global

Importância dos micro-organismos e da decomposição

Total de pag. que fazem referência ao meio ambiente

$9 \quad 7 \quad 2 \quad 1$

$\begin{array}{llll}10 & 8 & 9 & 9\end{array}$

\begin{tabular}{lllll}
\hline Porcentagem de pag. que fazem referência ao meio ambiente & $23,00 \%$ & $24,00 \%$ & $17,00 \%$ & $20,00 \%$ \\
\hline
\end{tabular}

Fonte: Elaborada pela autora.

Tabela 6: Análise dos livros didáticos de História.

\begin{tabular}{lcccc}
\hline \multicolumn{1}{c}{ LIVROS DE HISTÓRIA } & $\mathbf{2}^{\mathbf{0}}$ ano & $\mathbf{3}^{\mathbf{0}}$ ano & $\mathbf{4}^{\mathbf{0}}$ ano & $\mathbf{5}^{\mathbf{0}}$ ano \\
\hline Total de páginas do livro & 160 & 208 & 192 & 160 \\
\multicolumn{1}{c}{ TEMÁTICAS } & $\mathrm{N}^{\mathrm{o}}$ de páginas que fazem referência ao \\
& \multicolumn{4}{c}{ meio ambiente } \\
Diferentes paisagens naturais & - & - & 1 & - \\
Costumes das crianças indígenas em cuidar da natureza & - & 2 & - & - \\
Cuidados com a natureza & - & - & - & 1 \\
Total de pag. que fazem referência ao meio ambiente & 0 & 2 & 1 & 1 \\
\hline Porcentagem de pag. que fazem referência ao meio ambiente & $0,00 \%$ & $1,00 \%$ & $0,50 \%$ & $0,60 \%$ \\
\hline
\end{tabular}

Fonte: Elaborada pela autora.

história, em geral, estão mal preparados para enfrentar o debate ambiental, quando os PCNs (BRASIL, 1997a) trazem que "os fatos históricos podem ser entendidos como ações humanas significativas, escolhidas por professores e alunos, para análises de determinados momentos históricos.”. Esta abordagem poderia direcionar para a inserção do debate ambiental em vários pontos da história.

Ao fazer uma comparação dos livros didáticos de história com os das outras disciplinas analisadas anteriormente, reconheceu-se que, de todos os livros observados, os de história em geral são os que possuem menor abordagem ambiental com uma média geral de $0,5 \%$ de páginas fazendo referência ao tema. O livro em que há maior presença de assuntos sobre o ambiente é o livro do terceiro ano. Nele, $1 \%$ de páginas do livro trazem temas ambientais, comparado com o livro do segundo ano, no qual não existe nenhum tema sobre o assunto. Desta forma, os temas sobre o ambiente são pouco representativos nos livros didáticos de história. A perspectiva histórica da utilização e da relação com o ambiente das mais variadas civilizações em variadas épocas deveria ser foco principal da transversalidade da história.

\section{CONSIDERAÇÕES FINAIS}

Conclui-se que os livros didáticos abordam conteúdos com a temática ambiental, contendo trechos que o docente pode utilizar para inserir debates e reflexões sobre o ambiente, sendo que alguns trazem mais e outros menos trechos. Entretanto, a inserção desse tema está proposta, na maioria das vezes, de forma fragmentada e desvinculada da realidade do aluno, sem haver uma contextualização dos temas.

Os conteúdos sobre meio ambiente em que se pode trabalhar educação ambiental estão inseridos em suas 
EDUCAÇÃO AMBIENTAL NOS LIVROS DIDÁTICOS ADOTADOS NO ENSINO FUNDAMENTAL PELO MUNICÍPIO DE ACARAÚ-CEARÁ

páginas mais como uma formalidade e com o intuito de informar, não havendo uma proposta de trazer o tema para os estudantes discutirem e terem uma visão holística sobre o assunto.

Observou-se, ainda, que há uma carência nos livros didáticos no que se refere aos conteúdos sobre o ambiente, sendo mais presentes nos livros que têm uma proximidade maior com o ambiente, como é o caso de ciências e geografia, e menor nas disciplinas mais distantes, como história. Falta um olhar diferenciado e a presença de discussões mais relevantes, que estimulem o educando a pensar e agir criticamente acerca das questões ambientais.

\section{REFERÊNCIAS}

ABíLIO, F. J. P.; VILA, A. J. T.; ANDRADE, A. M. S.; MONTENEGRO, A. K. A. Meio ambiente e educação ambiental: uma análise crítica dos livros didáticos de ciências do ensino fundamental. In: SIMPÓSIO INTERNACIONAL PROCESSO CIVILIZADOR. João Pessoa: UFPB, 2004, (8).

BARDIN, L. Análise de conteúdo. Lisboa: Edições 70, 1977. v. 1.

BEZERRA, L. M. Projeto Buriti: Ciências. $2^{\circ}$ ao $5^{\circ}$ ano. 2. ed. São Paulo: Moderna, 2011.

BIANCHINI, D. C.; FANK, J. C.; SEBEN, D.; RODRIGUES, P.; BARROS, W. S. Sustentabilidade e educação ambiental na escola estadual de ensino fundamental. Revista Monografias Ambientais, v. 14, n. 1, p. 188-194, 2015. Disponível em: <http: //periodicos.ufsm.br/remoa/article/viewFile/18753> Acesso em: 12 Mar 2015.

BORGATTO, A. M. T.; BERTIN, T. C. H.; MARCHEZI, V. L. C. Àpis: Língua Portuguesa. $4^{0}$ e $5^{\circ}$ ano. São Paulo: Ática, 2011.

BRASIL. Parâmetros Curriculares Nacionais de $1^{\mathrm{a}}$ a $4^{\mathrm{a}}$ séries: ciências naturais. Brasília: MEC/SEF, 1997. v. 4. Disponível em: <http: //portal.mec.gov.br/seb/arquivos/pdf/livro04.pdf> Acesso em: 01 Abr 2018.

Parâmetros Curriculares Nacionais: Meio ambiente. Brasília: MEC/SEF, 1997.

Parâmetros curriculares nacionais: história. Brasília: MEC/SEF, 1998.

Lei 9.79527 de abril de 1999. Dispõe sobre Educação Ambiental e institui a Política Nacional de Educação Ambiental, e dá outras providências. Brasília, 1999.

Guia de livros didáticos: $1^{\mathrm{a}}$ a $4^{\mathrm{a}}$ série. Brasília: MEC, 2004.

CARVALHO, I. C. M. Educação ambiental: a formação do sujeito ecológico. 4. ed. São Paulo: Cortez editora, 2008.

CHANOSQUI-GUSSO, A. M.; FINAU, R. A. Rumo a novos letramentos: Letramento e alfabetização: Língua Portuguesa. $1^{\circ}$ ao $3^{\circ}$ ano. Curitiba: Base editorial, 2011.

CUBA, M. A. Educação ambiental nas escolas. Educação, Cultura e Comunicação, v. 1, n. 2, p. 23-31, jul./dez 2010.

DELIZOICOV, D.; ANGOTTI, J. A.; M., P. M. Ensino de Ciências: Fundamentos e métodos. 4. ed. São Paulo: Cortez, 2011.

DIAS, G. F. Educação Ambiental: Princípios e Práticas. 9. ed. São Paulo: Gaia, 2010.

FERREIRA, E. A transversalidade nas aulas de língua portuguesa: A educação ambiental em questão. Anais do SILEL, EDUFU, Uberlândia, v. 3, n. 1, p. 1-10, 2013.

FREITAS, N. K.; RODRIGUES, M. H. O livro didático ao longo do tempo: a forma do conteúdo. Santa Catarina, 2008. Disponível em: <http://www.udesc.br/arquivos/portal_antigo/ Seminario18/18SIC/PDF/074_Neli_Klix_Freitas> Acesso em: 13 Out 2015.

FRISON, M. D.; VIANNA J.; CHAVES, J. M.; BERNARDI, F. N. Livro Didático como instrumento de apoio para construção de propostas de ensino de Ciências naturais. Florianópolis, 2009. Disponível em: <http: //posgrad.fae.ufmg.br/posgrad/viienpec/pdfs/425.pdf.> Acesso em: 14 Abr 2015.

IBGE. Pesquisa: Área dos municípios: Acaraú. 2018. Disponível em: <https://www.ibge.gov.br/ geociencias-novoportal/organizacao-do-territorio/ estrutura-territorial/15761-areas-dos-municipios.html? $\mathrm{t}=$ destaques\&c=2300200> Acesso em: 01 Abr 2018.

LEANDRO, L. A.; GOMES, C. M.; CASTRO, K. N. V.; CâSTRO, E. M. N. V. O futuro da gestão socioambiental: uma análise crítica sobre a crise ambiental brasileira. Rev. Ges. Sust. Ambient., v. 4, n. 2, p. 144-162, 2015. 
LIMA, M. Porta Aberta: História $2^{\circ}$ ao $5^{\circ}$ ano. 1. ed. São Paulo: FTD, 2011.

MAESTU, J. Projeto Buriti: Geografia. $2^{\circ}$ ao $5^{\circ}$ ano. 2. ed. São Paulo: Moderna, 2011.

MALTHUS, T. Ensaios sobre a População. col. "Os Economistas”. 1. ed. São Paulo: Abril Cultural, 1798.

MARPICA, N. S.; LOGAREZZI, A. J. M. As "áreas de silêncio" das questões ambientais em livros didáticos de diferentes disciplinas. Ambiente \& educação, v. 13, n. 1, p. 35-52, 2008.

MARTINS, E. F.; GUIMARãES, G. M. As concepções de natureza nos livros didáticos de ciências. Pesquisa em Educação em Ciências, v. 4, n. 2, p. 1-14, 2002.

MELO, K. M. F.; GROENWALDO, C. L. Tema meio ambiente e sua inserção em duas coleções de livros didáticos de matemática para os anos finais do ensino fundamental. Revista Brasileira de Ensino de Ciência e Tecnologia, v. 5, n. 2, p. 27-46, 2012.

MORAES, F. A. A educação ambiental nos livros didáticos de ciências das séries iniciais do ensino fundamental. In: PUCPR (Ed.). IX CONGRESSO NACIONAL DE EDUCAÇÃO,EDUCARE, III ENCONTRO SUL BRASILEIRO DE PSICOPEDAGOGIA DA PUCPR. Paraná: Anais eletrônicos., 2009. Disponível em: <http://www.pucpr.br/eventos/educere/educere2009/ anais/pdf/3662_2047.> Acesso em: 04 Jan 2016.

OLIVEIRA, M. M. O processo de ensino aprendizagem na geografia: Uma revisão necessária. Revista OKARA: Geografia em debate, v. 2, n. 1, p. 151-170, 2008.

PRADO, J. S. S. Agora é hora: Alfabetização Matemática. $1^{\circ}$ ao $3^{\circ}$ ano. 1. ed. Curitiba: Base editorial, 2011.

SALES, A. B.; LANDIN, M. F. Análise da abordagem da flora nativa em livros didáticos de biologia usados em escolas de aracaju. Experiências em Ensino de Ciências, v. 4, n. 3, p. 17-29, 2009.

SANCHEZ, L. B.; LIBERMAN, M. P. Coleção fazendo e compreendendo: Matemática. $4^{0}$ e $5^{\circ}$ ano. 5. ed. São Paulo: Saraiva, 2011.

VIEIRA, S. R. A educação ambiental e o currículo escolar. Revista Espaço Acadêmico, n. 83, 2008.
XAVIER, F. N.; OLIVEIRA, I. C. F.; ARANTES, M. R.; SILVA, P. S.; NASCIMENTO, S. S.; SANTOS, S.; SANT'ANNA, V. L. L. O despertar da consciência ecológica na formação do educando: Um desafio para o processo pedagógico. Pedagogia em Ação, v. 3, n. 2, p. 72-98, 2011. 